\title{
Hydronephrosis in a Dog Related to Ovariosalpingohysterectomy
}

\author{
Lucas Zaiden $\odot^{1}$, Gabriel Lopes Germano ${ }^{1}$, Antônio Carlos Severino Neto $\odot^{1}$, \\ Reiner Silveira de Moraes ${ }^{2}$, João Marcelo Carvalho do Carmo ${ }^{3}$, Andreia Vitor Couto do Amaral ${ }_{\odot}^{4}$, \\ Bruna Ditzel da Costa Regalin ${ }^{4}$ \& Klaus Casaro Saturnino ${ }^{4}$
}

\begin{abstract}
Background: Hydronephrosis is the dilation of the pelvis and renal calyxes due to post-renal obstruction. The obstruction is often associated with extraluminal masses, blood clots and ureter ligation in castration procedures. Ureter ligation is reported as a malpractice. The renal function is reestablished if ligation is rapidly undone, but not for obstructions longer than four weeks. Often, clinical signs are results from months to years after the castration, when nephrectomy is the best therapeutic option. This paper aims to report a case of asymptomatic unilateral hydronephrosis in a 10-year-old dog caused by chronic ureter occlusion with Nylon 3.0 suture during an elective procedure.

Case: A 10-year-old female pinscher dog, spayed 3 years ago was admitted at the Surgery Department of the Veterinary Hospital of the Federal University of Jataí (HV-UFJ). The animal was taken for periodontal treatment. In the physical and laboratory examination (complete blood count, hepatic and renal biochemical tests) no significant and noteworthy alterations were found. Ultrasonographic examination showed no changes in the topography and echotexture of the left kidney, however the right kidney was not visualized, with an anechoic structure suggestive of advanced and severe hydronephrosis. Therefore, exploratory laparotomy was proposed to identify the observed structure, with the periodontal treatment considered for a later time. So, a retroumbilical incision was made, followed by linea alba and the removal of simple isolated suture remaining from previous surgical procedure. In the cavity, the viscera were isolated and the left kidney was identified, observing preserved anatomy. On the other hand, the right kidney had altered topography and morphology, being exposed after release of adhesions in adjacent structures. The right renal artery and vein were dissected and a double ligature was made. Then, the right ureter was dissected, observing marked dilatation in the proximal portion and the presence of local ligation with Nylon 3.0. Right ureterectomy and right nephrectomy were performed. After nephrectomy, the capsule was ruptured, observing dark fluid in it and absence of tissue compatible with renal parenchyma. The material was preserved in $10 \%$ formaldehyde and sent for histopathological examination. Histopathology revealed risk of rupture of the renal capsule due to the advance of renal degeneration and complete absence of parenchyma. However, contrary to the severity of the histopathological, surgical and ultrasonographic findings, the patient did not present clinical signs at the time of diagnosis. Discussion: In the intraoperative evaluation, the cause of the hydronephrosis was verified to be in fact the ligation of the ureter, which may have been accidental or due to the malpractice of the veterinarian surgeon. Other possible causes such as adhesions and granulomas were ruled out because the Nylon 3.0 suture was found in the proximal portion of the right ureter. It is believed that the patient may have presented clinical signs of hydronephrosis that may have been confused by the tutors as postoperative complications, changes that if identified and performed in time, could have avoided the occurrence or worsening of hydronephrosis and subsequent nephrectomy. Clinically, the bitch did not show clinical signs presented in the literature as consistent with hydronephrosis such as polyuria, polydipsia, abdominalgia, external fistula and anorexia. Therefore, it is believed that this case is one of the first reports of the occurrence of severe hydronephrosis without typical clinical manifestations of hydronephrosis. This fact raises a warning about the thorough monitoring in the postoperative period by owners and veterinarians, in addition to highlighting concerns regarding the occurrence of medical malpractice versus surgical accidents.
\end{abstract}

Keywords: castration, malpractice, nephrectomy, nylon.

${ }^{1}$ Veterinary Hospital; ${ }^{3}$ Post-graduation Department in Animal Science \& ${ }^{4}$ Veterinary Medicine Department, Universidade Federal de Jataí (UFJ), Jataí, GO, Brazil. ${ }^{2}$ Department of Nephrology and Urology. Universidade Estadual Paulista - Júlio de Mesquita Filho (Unesp), Botucatu, SP, Brazil. CORRESPONDENCE: A.V.C. Amaral [andreiavcvet@ufj.edu.br]. Departamento de Medicina Veterinária - UFJ. Campus Jatobá. BR 364, km 195 nº 3800. CEP 75801-615 Jataí, GO, Brazil. 


\section{INTRODUCTION}

Hydronephrosis is an illness characterized by dilation of the pelvis and renal calyxes when in the presence of post-renal obstruction being unilateral or bilateral [7]. In cats, it is often associated with obstructive feline lower urinary tract diseases (FLUTD), such as calculi, neoplasms, inflammation and extraluminal masses that lead to compression of the ureter [3]. Less frequent causes include obstructions by blood clots in the renal pelvis or ureter, ectopic ureter, solidified blood calculus and ureter ligation in castration procedures $[4,5,7,8,14]$.

Hydronephrosis secondary to ureter ligation in castration procedures is mainly related to malpractice situations or surgeries in which there was no correct development of the surgical technique [15]. The clinical presentation of the affected patient may occur from months to years after the procedure. Ureteral compression can result in uremic crises, changes in the morphology of the kidney and ureter ipsilateral to the occlusion, and loss of renal function [6] leading to the occurrence of clinical manifestations such as pain on abdominal palpation [13], increased abdominal volume [15], vomiting, anorexia, diarrhea [7], weight loss [8], dehydration [5], polyuria, polydipsia and urinary incontinence [6].

Hydronephrosis secondary to ureteral obstruction is a condition of emotional impact for both owner and veterinarian [9]. Thus, the present study aims to report a case of asymptomatic unilateral hydronephrosis in a 10-year-old pinscher bitch caused by chronic ureter occlusion with nylon 3.0 suture during an elective procedure as well as present the macro and microscopic findings of the affected kidney.

\section{CASE}

A 10-year-old Pinscher female dog, spayed 3 years ago, weighing $6.3 \mathrm{~kg}$ and with black and white fur color was admitted at the Small Animal Surgery Department of the Veterinary Hospital of the Federal University of Jataí (HV-UFJ). The main owner's complaint was the presence of bacterial plaques adhered to the teeth and moderate halitosis. Therefore, the reason for the consultation was to assess the patient for further periodontal treatment.

Physical examination revealed a respiratory rate (RR) of $40 \mathrm{bpm}$, heart rate (HR) of $160 \mathrm{bpm}$, respiratory and cardiac auscultation without changes, capillary filling time $(\mathrm{CFT})<2 \mathrm{~s}$, normal colored ocular mucosa and congested gingival mucosa, femoral pulse strong and rectal temperature (RT) of $38.5^{\circ} \mathrm{C}$. The animal was slightly dehydrated $(<5 \%)$ and without lymphadenomegaly. Therefore, to perform the preoperative tests, ultrasound examination of the four abdominal quadrants (US), complete blood count (CBC) (erythrogram, white blood cell count and platelet count), hepatic biochemistry (alanine aminotransferase - ALT and alkaline phosphatase - FA) and renal biochemistry (urea and creatinine) were requested at first, in addition to blood investigation for hematozoa.

Considering the availability of periodontal treatment only in the week following the first visit, preoperative antibiotic therapy was started with sulfamethoxazole and trimethoppine ${ }^{1}\left[\right.$ Bactrim $^{\circledR}-15 \mathrm{mg} / \mathrm{kg}$, po, BID, for 7 days] and ultrasound was scheduled for the week following the day of the procedure. The erythrogram revealed mild polycythemia (8.5 - Ref. 5.5-8.4 $\times 10^{6} / \mu \mathrm{L}$ ) and hyperproteinemia (8.2 Ref. 6.0$8.0 \mathrm{~g} / \mathrm{dL}$ ). Hepatic and renal biochemistries showed a slight change, with attention only to creatinine, which registered a value slightly higher than the maximum limit (1.6 Ref. 0.5-1.5 mg/dL). The search for hematozoa was negative.

In the following week, 7 days after the first admission, an ultrasound examination of the patient (fasted) was performed for preoperative evaluation. The US revealed a slightly heterogeneous hepatic echotexture, gallbladder with altered content and mild presence of biliary sludge, urinary gallbladder with the presence of a stone measuring approximately $0.1 \mathrm{~cm}$, left kidney preserved without hypertrophy (Figure 1A) and no visualization of the right kidney, uterus and ovaries. In the topography of the right kidney (Figure 1B), an oval, thin-walled, hyperechoic structure distended by anechogenic content was visualized, measuring approximately $7.9 \mathrm{~cm}$ in length by $4.6 \mathrm{~cm}$ in height, suggesting advanced/severe hydronephrosis.

Given the ultrasonographic findings, considering the animal's age, surgical risk and possible systemic repercussion of the hydronephrosis suggested at US, the clinical scenario was presented to the owners and surgical intervention was proposed through an exploratory laparotomy to identify the structure visualized on the imaging exam. Aware of the importance of this procedure before the periodontal treatment itself, as well as for the animal's life, the owners agreed and 


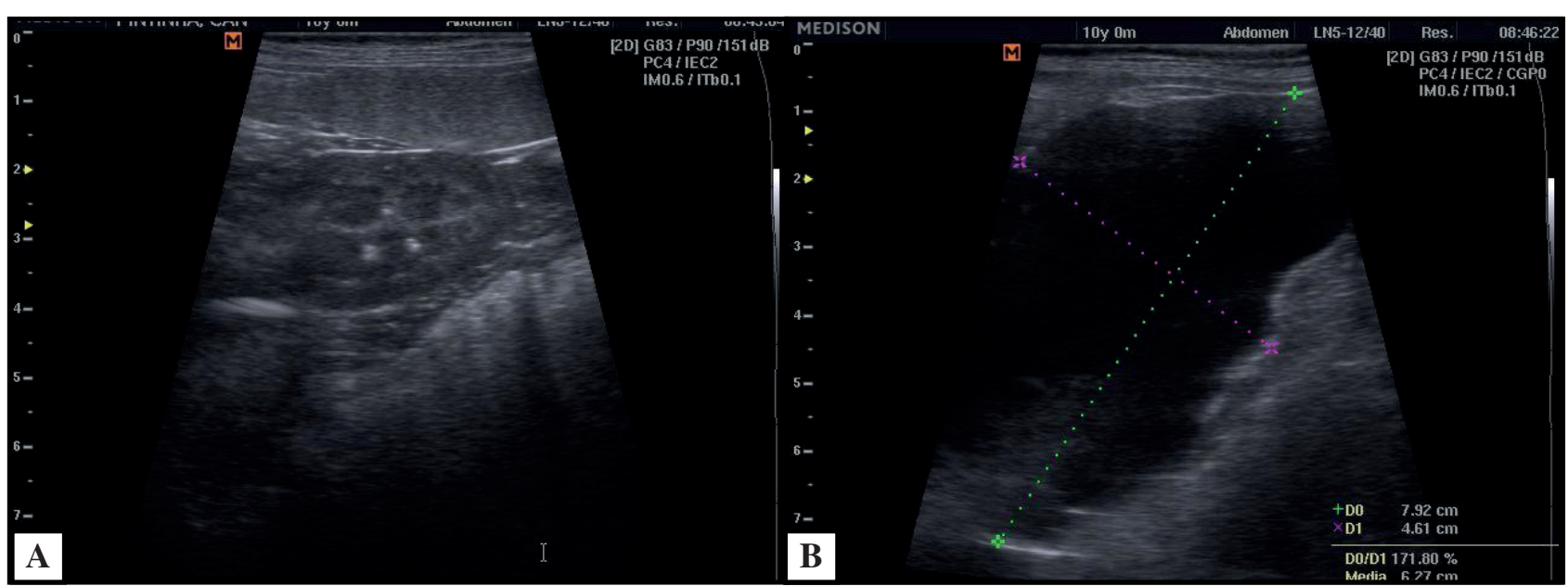

Figure 1. Abdominal ultrasound image of a 10-year-old female dog showing a preserved left kidney (A) and topography of the right kidney (B) showing an oval, thin- walled, hyperechoic structure distended by anechogenic content.

an exploratory laparotomy was then scheduled for the week following the US.

The case was carefully evaluated and it was not judged as an emergency, as the animal did not show clinical signs consistent with severe renal impairment and maintained all vital parameters stable. Therefore, the patient was closely monitored, having the erythrogram, leukogram, platelet count and, liver and kidney biochemical exams repeated before the surgical intervention. No changes in erythrogram, leukogram, platelet count and creatinine were seen, but a slight change in urea $(41 \mathrm{mg} / \mathrm{dL})$.

In exploratory laparotomy, a retroumbilical incision was made with cranial enlargement of $3 \mathrm{~cm}$, followed by a lineal incision with removal of the isolated non-absorbable single stitches found in the region, as the patient had undergone ovariosalpingohysterectomy 3 years before in a nonidentified veterinary hospital. With access to the abdominal cavity, the isolation of the abdominal viscera was performed using pads moistened with pre-warmed ringer lactate solution. Then, the left kidney, which had preserved topography and anatomy, was identified and an incision was made in the peritoneum to release the right kidney, as well as dissection of adhesions in structures adjacent to the right kidney to allow its visualization. Once the access was released, the presence of a structure compatible with the right kidney was verified, but with altered topography and anatomy (Figure 2). The renal artery and vein were dissected and ligated separately with a double ligature using a 2.0 poliglecaprone thread, then sectioning the vessels between the ligatures.

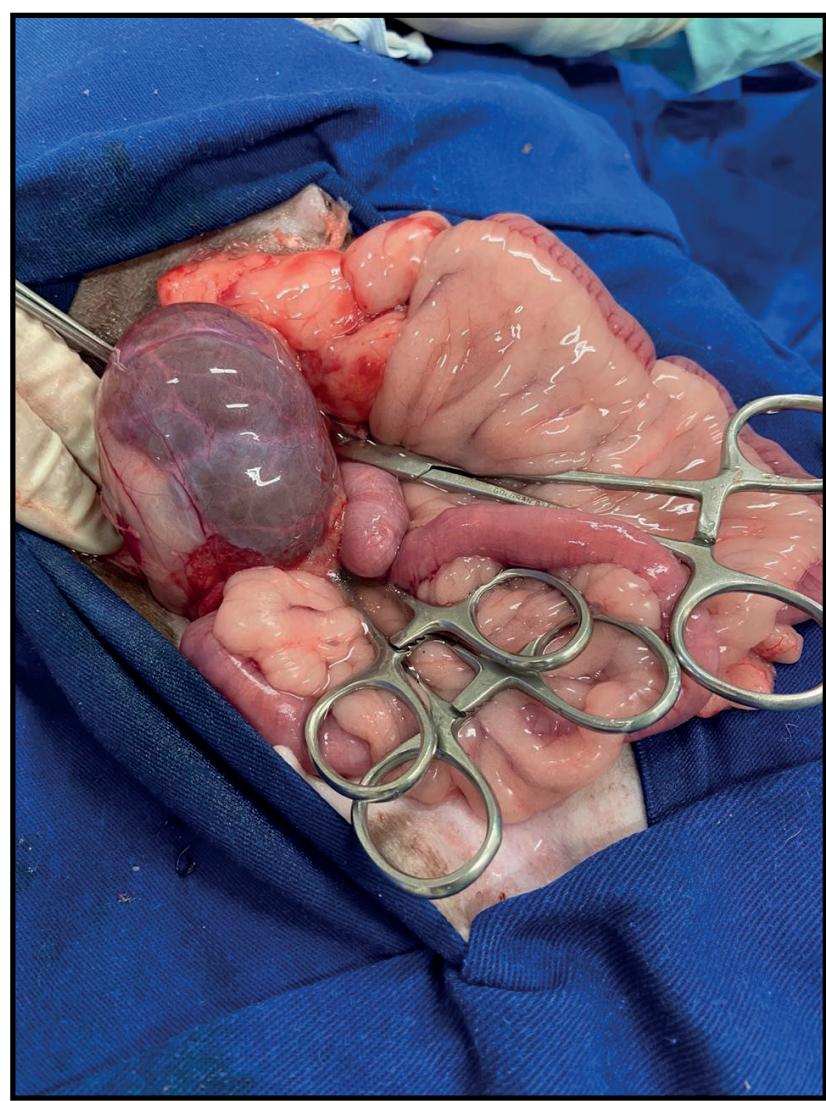

Figure 2. Widely distended structure, filled with liquid content compatible with na isolated right kidney in exploratory laparotomy.

After releasing the main renal vessels, dissection of the right ureter was performed, which showed marked dilatation in its proximal portion, where the presence of non-absorbable nylon 3.0 suture was verified. During the performance of double ligation in the proximal portion of the ureter with 2.0 poliglecaprone suture, there was a rupture in the dilated portion due 
to the friable aspect that it was at the moment. The entire extension of the right ureter was evaluated and no other alterations were verified in its distal portions to the kidney. Therefore, a total unilateral ureterectomy was performed. Finally, the structures adhered to other portions of the right kidney were divulged and this was released and its excision performed (Figure 3 ).

After performing the right nephrectomy, the capsular structure was disrupted (Figure 4) and the presence of a dark colored liquid with a characteristic urine odor was verified. There was no internal structure to the capsule consistent with renal parenchyma. The sample was preserved in $10 \%$ formaldehyde solution and sent for histopathological analysis. Macroscopic findings revealed a capsular structure measuring

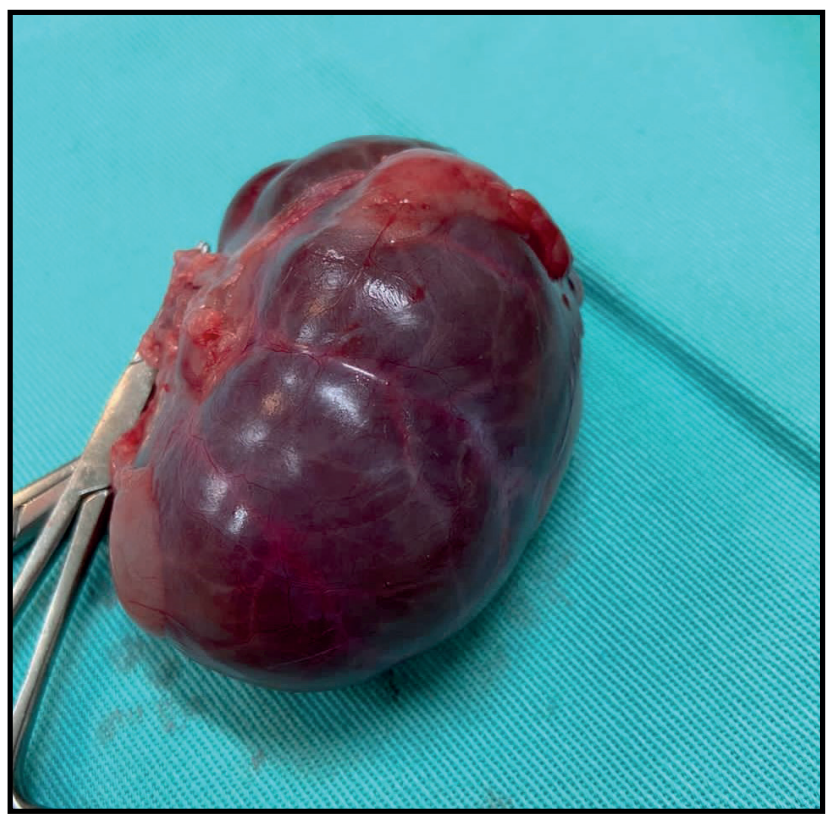

Figure 3. Structure compatible with a right kidney obtained in total unilateral nephrectomy during exploratory laparotomy procedure.

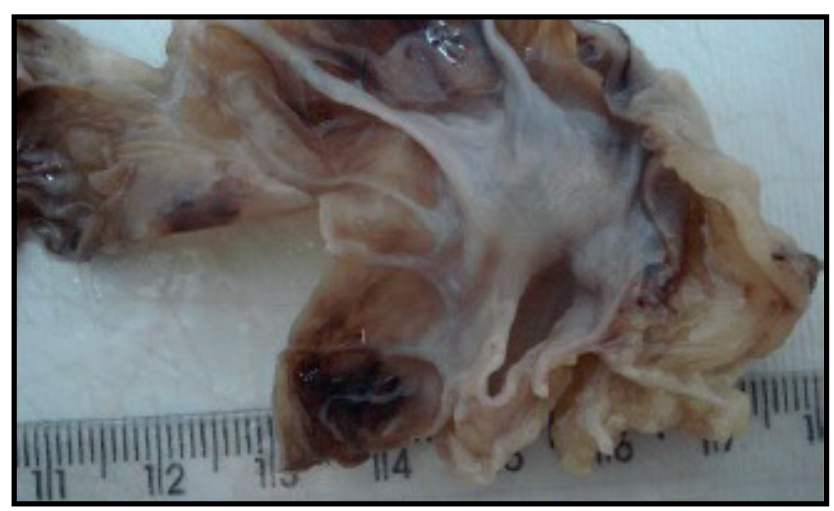

Figure 5. Capsular structure, without the presence of renal parenchyma and with connective septa visualized during macroscopic evaluation. approximately $7.0 \times 5.0 \mathrm{~cm}$ in diameter partially surrounded by adipose tissue. Upon sectioning, it was found to be a capsular structure with moderate presence of vascularization, without parenchyma and with formation of chambers interspersed by connective septa (Figure 5).

Microscopy revealed a sample with renal tissue residues and moderate progressive vascular compression, in addition to severely atrophied glomeruli, as well as a moderate lymphohistiocytic infiltrate (Figure 6). The morphological diagnosis resulted in severe and diffuse renal pelvic dilatation, associated with severe and diffuse atrophy of the renal cortex and medulla, thus being a case of diffuse and severe renal atrophic hydronephrosis.

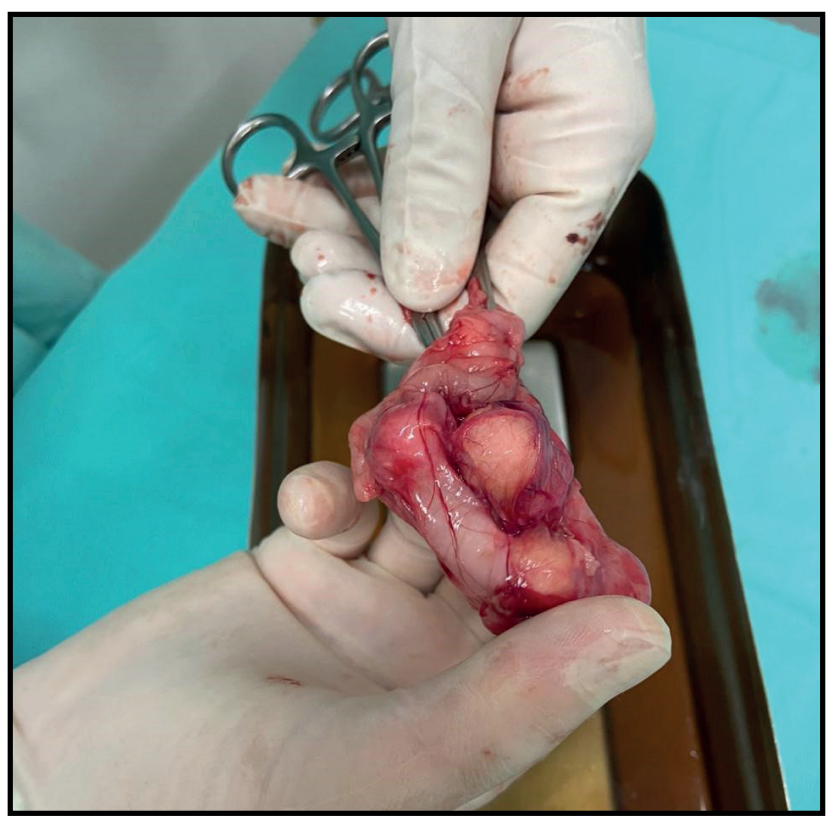

Figure 4. Renal capsule with moderate vascularity, no parenchyma and filled with dark yellow liquid (surgical procedure box).

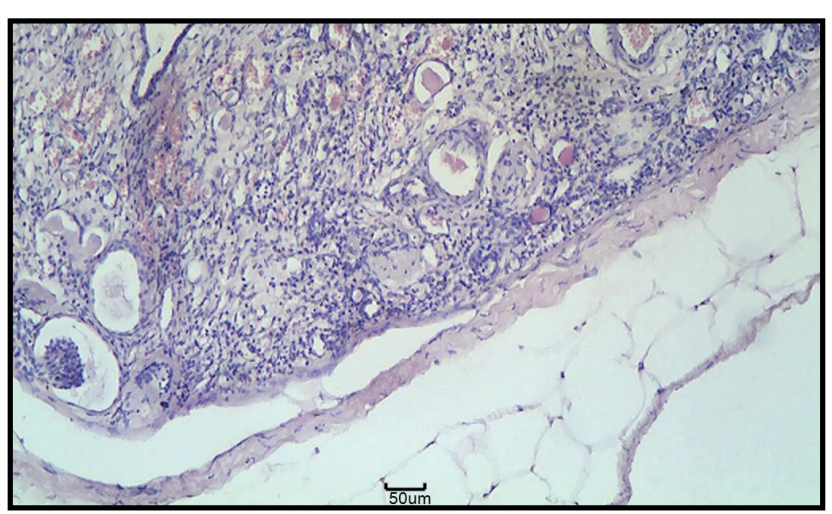

Figure 6. Microscopy of capsular structure obtained during right unilateral total nephrectomy with evidence of compressed blood vessels, severely atrophied glomeruli and moderate presence of lymphohistiocytic infiltrate. 


\section{DISCUSSION}

Undoubtedly, the obstruction of the ureter was caused by ligation with a 3.0 nylon thread. However, the ligation may have been accidental, taking place in elective surgery performed by an experienced surgeon; or arising from medical malpractice, by an act performed by a veterinarian with a lack or deficiency of technical knowledge of the profession [15]. The obstruction of the ureter was not caused by the formation of adhesions, granulomas or fistulous tracts [1,2], as a nylon suture and ligature were found in the ureter on the affected side, a fact that caused the obstruction and hydronephrosis.

It can be conjectured that the patient presented clinical signs that may have been due to more routine complications of an $\mathrm{OSH}$, however without thorough follow-up and investigation of possible surgical failures. In the same way that discrete signs of hydronephrosis may have appeared and not been noticed by the owners. It is clear and undisputed that if the obstruction of the ureter caused by the ligation were reversed within a few days, the course of hydronephrosis and nephrectomy could be avoided or minimized [15].

Unlike other cases in the literature, the animal in this report did not develop clinical signs of hydronephrosis such as polyuria, polydipsia, hematuria, abdominalgia, external fistula and anorexia [11]. Mesquita and collaborators reported a case of hydronephrosis due to obstruction of the ureter with a Nylon clamp, in which the animal presented signs of progressive weight loss, emesis and anorexia at the first visit to the hospital, referring to an animal 4 years younger than the one in this report and with surgical procedure performed in a castration campaign, which can be considered a major problem in Brazil [8].

Castration campaigns have increased in recent years aiming at population control of dogs and cats as well as zoonotic diseases. Therefore, seeking to serve the low-income population, non-governmental organizations and protective entities, for example, have been involved in the performance of castration procedures, in which surgical asepsis principles and manipulation techniques are neglected. Although it is considered a low-complexity procedure, castration that is not carried out properly and by a trained team can lead to the animal's death or even cause significant complications such as hydronephrosis [15].
Another case of unilateral hydronephrosis in a dog brings the occurrence of partial obstruction of the ureter from the formation of granuloma after castration. Similarly, in this case, the animal was presented with complaints of polyuria, polydipsia and persistent incontinence for one month, in addition to significant changes in urea (131.2 - ref. 9.1-31.9 mg/dL) and creatinine (11.1 - ref. 0.2-1.6 mg) levels /dL) serum [6]. In the present report, the animal presented subtle changes in creatinine ( 1.6 - ref. $0.5-1.5 \mathrm{mg} / \mathrm{dL})$ in a first moment and urea (41 - ref. $15-40 \mathrm{mg} / \mathrm{dL})$ in a second moment, which are assumed to be due to the existent mild dehydration, justifying such changes at both times.

There is also a report of hydronephrosis in dogs due to abdominal trauma [10] and congenital causes $[12,13]$. Meanwhile, in felines the various causes include extramural obstructions due to leiomyosarcoma [4] and complications from ovariohysterectomy [9]. Studies show that there may be situations in which there is no evidence of clinical signs, since hydronephrosis has a progressive character and, therefore, signs may appear with the progression of the disease [11]. However, macro and microscopic findings revealed a severe and advanced condition of the disease with risk of rupture of the renal capsule, given the absence of renal parenchyma.

Therefore, this case constitutes the first case of severe hydronephrosis reported after complete obstruction of the ureter with a Nylon 3.0 suture in a dog without the occurrence of clinical manifestations consistent with hydronephrosis. In addition, the histopathological findings revealed the presence of a severe condition with risk of rupture of the renal capsule, given the advance of renal degeneration and complete absence of parenchyma.

\section{MANUFACTURERS}

${ }^{1}$ IDEXX Laboratories Inc. Westbrook, ME, USA.

${ }^{2}$ Roche Farmacêutica. Rio de Janeiro, RJ, Brazil.

${ }^{3} \mathrm{JP}$ - Indústria Farmacêutica. Ribeirão Preto, SP, Brazil.

${ }^{4}$ Plast Suture - Indústria, Comércio e Representação de Fios Cirúrgicos. Fortaleza, CE, Brazil.

${ }^{5}$ M\&M Química - Comercialização de Produtos Químicos. Diadema, SP, Brazil.

Acknowledgments. To the Veterinary Hospital of the Federal University of Jataí, the staff involved in imaging and surgical procedure.

Declaration of interest. The authors report no conflicts of interest. The authors alone are responsible for the content and writing of paper. 


\section{REFERENCES}

1 Adin C.A. 2011. Complications of ovariohysterectomy and orchiectomy in companion Animals. Veterinary Clinics of North America: Small Animal Practice. 41: 1023-1039.

2 Atallah F.A., Silva R.S., Ramos M.L, M., Oliveira A.L.A., França T.N. \& Brito M.F. 2013. Complicações pós-cirúrgicas em cadelas submetidas a ovário-histerectomia no Rio de Janeiro. Revista Brasileira de Medicina Veterinária. 35: 61-69

3 Bovens C. 2011. Feline Lower Urinary Tract Disease - A diagnostic approach. Feline Update. 1: 1-3. [Fonte: https:// www.langfordvets.co.uk/media/1260/feline-update-autumn-2011-revised-030713.pdf]

4 Evans D. \& Fowlkes N. 2016. Renal leiomyosarcome in a cat. Journal of Veterinary Diagnostic Investigation. 28(3): 315-318.

5 Gopegui R.R., Espada Y. \& Majó N. 1999. Bilateral hydroureter and hydronephrosis in a nine-year-old female German Shepherd dog. Journal of Small Animal Practice. 40: 224-226.

6 Kanazono S., Aikawa T. \& Yoshigae Y. 2009. Unilateral Hydronephrosis and Partial Ureteral Obstruction by Entrapment in a Granuloma in a Spayed Dog. Journal of the American Animal Hospital Association. 45: 301-304.

7 Kim J., Oh D., Cho J., Kim S. \& Yoon J. 2021. Recurrent hydronephrosis and spontaneous renal rupture caused by lymphoplasmacytic inflammation in a cat. Veterinarni Medicina. 66(2): 80-86.

8 Mesquita L.R., Rahal S.C., Matsubara L.M., Mamprim M.J., Foschini C.R., Faria L.G. \& Kano W.T. 2015. Bilateral hydronephrosis and hydroureter after ovariohysterectomy using nylon cable tie: a case report. Veterinarni Medicina. 60(1): 52-56.

9 Plater B.L. \& Lipscomb V.J. 2020. Treatment and outcomes of ureter injuries due to ovariohysterectomy complications in cats and dogs. Journal of Small Animal Practice. 61: 170-176.

10 Raposo T.M.M., Varallo G.R., Huppes R.R., Brum A.M. \& Nardi A.B. 2013. Dog with hydronephrosis due to abdominal trauma. Pakistan Veterinary Journal. 33(4): 526-528.

11 Rousset N., Abbondati E., Posch B., Owen L.J. \& Herrtage M. 2011. Unilateral hydronephrosis and hydroureter secondary to ureteric atresia, and uterus unicornis in a young terrier. Journal Small Animal Practice. 52(8): 441-444.

12 ahal M., Haziro lu R., Özkanlar Y. \& Beyaz L. 2005. Bilateral hydronephrosis and hydroureter in a German shepherd dog. Ankara Üniversitesi Veteriner Fakultesi Dergisi. 52: 193-196.

13 Schwarz T., Simpson M., Saunders J. \& Bommer N. 2020. Obstructed left retrocaval ureter in a dog. Veterinary Record Case Report. 8: 1-4.

14 Selgas A.G., Scase T.J. \& Foale R.D. 2014. Unilateral squamous cell carcinoma of the renal pelvis with hydronephrosis in a cat. Journal of Feline Medicine and Surgery. 16(2): 183-188.

15 Silva E.A.A.C., Jesus T.B., Muramoto C., Ribeiro Filho C.H.A., Dórea Neto F.A., Quessada A.M., Martins Filho E.F. \& Costa Neto J.M. 2016. Postoperative complication of ovariohysterectomy in a female dog - case report. Revista Brasileira de Medicina Veterinaria. 38(1): 9-16. 